\title{
GCU
}

Glasgow Caledonian

University

University for the Common Good

\section{Virtual reality for simulation and evaluation: technology acceptance models for automotive consumer electronics}

Charissis, Vassilis; Bram-Larbi, Kweku; Lagoo, Ramesh; Wang, Shu; Khan, Mohammed

Soheeb; Altarteer, Samar; Harrison, David; Drikakis, Dimitris

Published in:

$\mathrm{HCl}$ International 2021 - Late Breaking Papers: Multimodality, eXtended Reality, and Artificial Intelligence. HCII 2021

DOI:

10.1007/978-3-030-90963-5_18

Publication date:

2021

Document Version

Author accepted manuscript

Link to publication in ResearchOnline

Citation for published version (Harvard):

Charissis, V, Bram-Larbi, K, Lagoo, R, Wang, S, Khan, MS, Altarteer, S, Harrison, D \& Drikakis, D 2021, Virtual reality for simulation and evaluation: technology acceptance models for automotive consumer electronics. in C Stephanidis, M Kurosu, JYC Chen, G Fragomeni, N Streitz, S Konomi, H Degen \& S Ntoa (eds), $\mathrm{HCl}$ International 2021 - Late Breaking Papers: Multimodality, eXtended Reality, and Artificial Intelligence. HCII 2021. Lecture Notes in Computer Science, vol. 13095, Springer, pp. 219-234, 23rd International Conference on Human-Computer Interaction, 24/07/21. https://doi.org/10.1007/978-3-030-90963-5_18

\section{General rights}

Copyright and moral rights for the publications made accessible in the public portal are retained by the authors and/or other copyright owners and it is a condition of accessing publications that users recognise and abide by the legal requirements associated with these rights.

Take down policy

If you believe that this document breaches copyright please view our takedown policy at https://edshare.gcu.ac.uk/id/eprint/5179 for details of how to contact us. 


\title{
Virtual Reality for Simulation and Evaluation: Technology Acceptance Models for Automotive Consumer Electronics
}

\author{
V. Charissis ${ }^{1[0000-0002-4195-843 X]}$, K. F. Bram- Larbi ${ }^{1}$, R. Lagoo ${ }^{2}$, S. Wang ${ }^{3}$, S. Khan ${ }^{1}$, \\ S. Altarteer ${ }^{4}$, D.K. Harrison ${ }^{1}$ and D. Drikakis ${ }^{50000-0002-3300-7669]}$ \\ ${ }^{1}$ Glasgow Caledonian University \\ School of Computing, Engineering and Built Environment, \\ Glasgow, UK \\ ${ }^{2}$ Core Lab + Ltd., \\ Research \& Development \\ Glasgow, UK \\ ${ }^{3}$ Volkswagen, \\ Research \& Development \\ Beijing, China \\ ${ }^{4}$ Dar Al-Hekma University, \\ School of Design and Architecture, \\ Jeddah, Saudi Arabia \\ ${ }^{5}$ University of Nicosia, \\ Defence and Security Research Institute, \\ Nicosia, Cyprus
}

\begin{abstract}
The design, development and evaluation of consumer electronics pose many challenges in the transition from initial concept to final product market release. In the automotive sector, in particular, due to the nature of these devices and to alleviate users' safety concerns, the evaluation of such devices could be primarily performed in simulated and virtual environments. Device functionality can be evaluated objectively by measurement of user performance indicators. User acceptance of these technologies and attitude towards future use is, however, more difficult to formally access, but is considered as important a determinant of the success or failure of a product. The paper presents the virtual simulation requirements of two prototype AR HUD systems and two variations of Technology Acceptance Models (TAM) designed exclusively for their evaluation. The reasoning behind virtual simulations and utilisation of TAM variants in accessing and predicting user experience outcomes and intentions is discussed. In conclusion, a future plan for examining further the virtual simulation environments and additional TAM structures is proposed.
\end{abstract}

Keywords: Augmented Reality, Virtual Reality, Technology Acceptance Model, Collision Avoidance, Head-Up Display, Smart Cities, Simulation 


\section{Introduction}

En masse production of consumer electronics has to deliver on their functionality promise and ought to comply with several quality standards. Additionally, they have to fulfil users' expectations and support future consumer electronics ecosystems. As such, the development of a successful product is usually not a one-step process but adheres to a certain sequential methodology, which relies on the development of the product through a series of experimentations and adjustments as required. One of the most important parts of this sequence is the User Experience (UX) evaluation of the product during the different stages of design, research and development period. Failure to satisfy and produce a conducive user experience typically results in an overall commercial failure. Physical prototypes could facilitate an initial appraisal, yet the production of different physical prototype models might prove costly and potential changes to the product could not be directly accommodated to the same testing model. Health and safety risks might also hinder the development and testing process of consumer electronics, particularly in the automotive or building sector.

Virtual and Augmented Reality (VR/AR) has already been employed by various industries to test and improve products before physical prototyping and manufacturing [1]. To this end, the development of VR immersive simulators could offer the luxury of infinite repetitions of an experiment and easy customisation of a product. Furthermore, the evaluation of any product's efficiency can be processed in a safe virtual environment enabling the developers and the users to identify potential issues in manufacturing and usage issues that could not be performed in real-life [2].

For this reason, we developed a Virtual Reality Driving Simulator (VRDS Lab) designed to evaluate various in-vehicle infotainment systems [3, 4]. The paper will present the design and evaluation process of two prototype AR HUD interfaces, aiming to increase safety by reducing driver distraction typically caused by in-vehicle information or/and passengers respectively.

The first AR HUD system employs gesture recognition for the direct manipulation of selected AR icons which could present infotainment data in a timely and safe manner to the driver [3]. The second interface provides an assortment of infotainment activities (i.e. educational information, games, navigation data, and local news) that could be superimposed in the real-surroundings, and occupy the rear passengers during commuting or long-distance travelling, improving the driver's attention to the road.

This paper will present the use of customised Technology Acceptance Models (TAM) applied to measure the users' experience, satisfaction, and acceptance of the emergency technologies tested in the virtual environment [5,6]. The TAM results of the two aforementioned cases of AR HUD interfaces will be discussed in contrast to the simulation performance achieved by the users. Finally, the paper will discuss the potential of the VR evaluation of various product designs, aiming to perfect and appraise them before the final level of production and will offer a development framework for the customisation of TAM constructs for VR evaluations in Consumer Electronics. 


\section{Consumer Electronics}

\subsection{Current Consumer Electronics' Trends}

Technological advancements have enabled the development of current consumer electronics that follow an exponential progression in the miniaturisation of the devices with increased computational processing speed and capabilities. Yet, this fast pace provision of systems and devices can present major challenges with regards to users' expectations, satisfaction and acceptability [7]. Once these consumer electronics (i.e. mobile phones, smart-tablets, smart-watches and televisions amongst other devices) are already developed in a functional prototype version, numerous user-experience (UX) methods could be employed to assess the level of user satisfaction [8].

To this end, user experience and intention for purchasing and using new electronic products could be focused on the user's expectations and related to products' performance, the effort required to operate it, the social influence that could enhance users' image, and the facilitating conditions, which are stemming from the unified theory of acceptance and use of technology (UTAUT) [9]. Yet, particular devices and systems that could affect user's safety (i.e. car consumer electronics) are typically tested in simulated and/or controlled physical environments that could mask any potential user hazards $[2,4]$. In previous work, during the design and development process, it was observed that the evaluation performed through immersive simulation (VR Simulation) could offer a better understanding of users' expectations and intentions to use the prototype product $[4,5,10]$.

\subsection{Vehicular prototype devices - AR HUD Case Studies}

To define a framework for the development of a Technology Acceptance Model (TAM) that could facilitate the evaluation for similar consumer electronics designed for the automotive sector, this work will present and discuss two case studies related to AR HUD systems and the TAMs designed for the evaluation of each system.

The aforementioned Head-Up Display devices currently offer an alternative to traditional dashboard infotainment systems (Head-Down Displays) with the immediate benefit of maintaining the driver's gaze on the road [11-13]. The HUD design mantra largely involves the presentation of useful information directly in the driver's field of view by superimposing them to the windscreen producing significant advantages in contrast to HDD [13, 14]. To superimpose the selected information, HUD devices employ a projection system (i.e., image projector or laser projector) and a glass combiner that enhances the projected image. The majority of the current commercial versions of HUDs are falling within the small to medium estate and as such do not augment information directly to the real-environment. Our previous studies focused on the large-scale estate HUDs which utilised Augmented Reality to superimpose information directly onto the real-objects in close proximity to the vehicle enabling the driver to identify potential hazards and reduce the probability of collisions $[13,15]$.

Previous studies in the provision of crucial information to the driver via AR HUD system were evaluated primarily to define the actual driver performance benefits in relation to braking response times (RTs), manoeuvring choices and ultimately user's 
ability to avoid imminent collisions with the use of the prototype HUD systems in contrast to existing dashboard bound HDD systems. Although the HCI designs were meticulously tested in different driving simulators and driving scenarios revealing the significant performance gains achieved with the use of AR HUDs, it had not yet fully assessed the drivers' intention to use and subsequently purchase these devices in the future [15-17].

The necessity to define and quantify the users' behavioural intentions was deemed essential in the latest two projects which are related to the provision of in-vehicle infotainment. These two projects are presented in this paper as case studies, whilst aiming to minimise the risk of driver distraction and consequently reduce collision occurrences. These two AR HUD prototypes are presented succinctly below.

(a) Driver's AR HUD system: This system presents three types of information namely navigation, mobile phone text messages and phone calls as shown in Figure 1. The latter could be withheld during manoeuvring or high-speed travelling. In this case, a text message provided the caller's contact details that the driver could call when a safe driving pattern is resumed. In contrast to current HUD systems that only present some information mirroring the HDD functions, the proposed AR HUD is fully interactive as the driver can operate the AR icons through a simple gesture recognition interface. This approach offers a direct manipulation capability to the user interface that imitates reallife interactions and enables the driver to access infotainment data safely $[3,4,13]$.

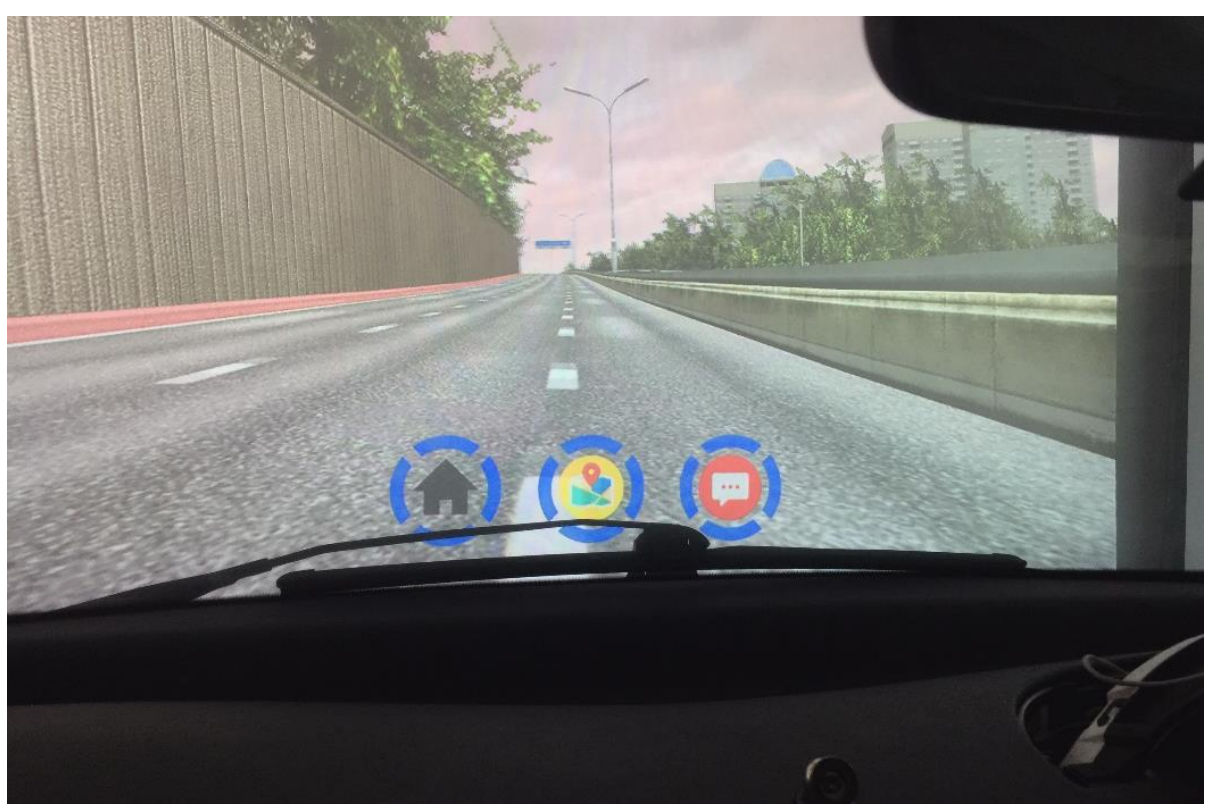

Fig. 1. Case 1:Driver's AR HUD and gesture recognition for controlling infotainment sources.

(b) Passenger's AR HUD system: This second system is designed explicitly for the passengers to present infotainment activities that enrich daily commuting or long-distance travelling whilst reducing the interaction with the driver. This approach aims to 
reduce driver distraction by proxy of increasing the distraction of the passengers. The in-vehicle passenger distractions are responsible for a significant number of collisions, particularly when the rear passengers are children [18]. The provision of the AR HUD infotainment could also use the external scenery to superimpose educational information and games. The interaction with the aforementioned activities is performed with the use of console controllers as illustrated in Figure 2.

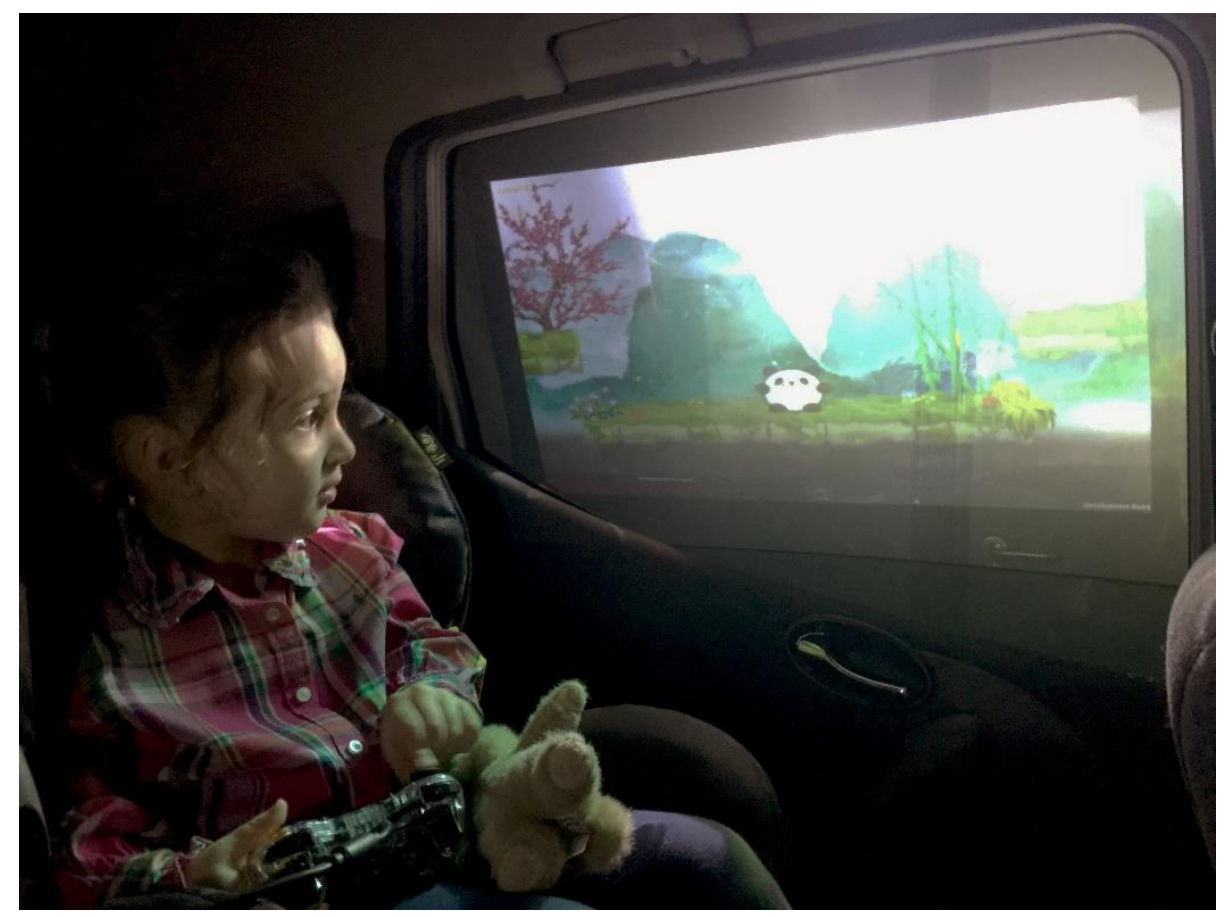

Fig. 2. Case2: Passengers' AR HUD system for controlling infotainment sources.

Both systems were evaluated in a custom-built VR driving simulator described in detail in the following section. The same driving scenario was applied following on from previous AR HUD systems and collision avoidance interfaces' evaluations [4,5,13]. The driving scenarios entailed several potential collisions based on real-scenarios provided by the local traffic police department. Maintaining uniformity in the evaluation systems, environment and scenarios was deemed essential for future comparison and evaluation purposes. In the following sections, the paper will further elaborate on the differences and similarities of the evaluation TAM tool that have been designed for each system. 


\section{Simulation}

The vast majority of electronic and engineering products are typically tested at a physical or virtual prototype level to identify the benefits and drawbacks of each system. This process is primarily concerned with the functionality of the systems, yet, the identification of User Experience (UX) and acceptability of the provided technologies, products and services is also an essential requirement. In particular, products such as software applications and small devices could be evaluated through functional prototypes.

However, this is not the case for systems and/or devices which need to be incorporated in larger products such as vehicles $[2,15]$. The evaluation limitations could further extend in safety and ethical considerations. In the case of new in-vehicle systems such as car infotainment devices that could affect a driver's response time (RT) to potential collision situations the user evaluation, at least at the first stages, should comply with strict regulations before performing physical prototype testing.

The provision of a simulation that could replicate closely the majority of the affecting attributes and conditions offers an ideal testing environment. To this end, the employment of VR technology for driving simulation enabled us to simulate a large range of configuration options without the need to build a physical mock-up. Based on the accurate representation of an existing motorway environment in Scotland, we simulated the effects of different icon types, positioning, and global calibration parameters [15]. Using spatially immersive, stereoscopic projections we achieved a simulation at 1:1 scale including effects of depth perception and weather conditions as Figure 3 shows.

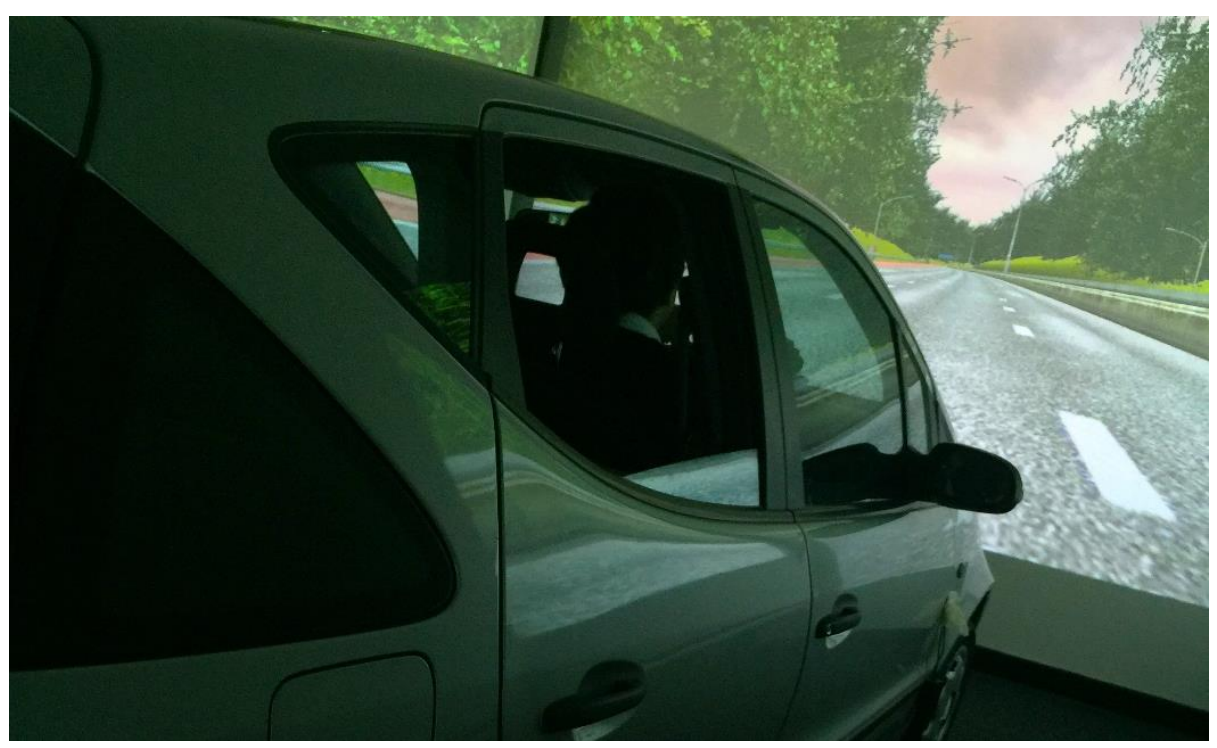

Fig. 3. A photograph of the Virtual Reality Driving Simulator laboratory (VRDS Lab) during the user evaluations 

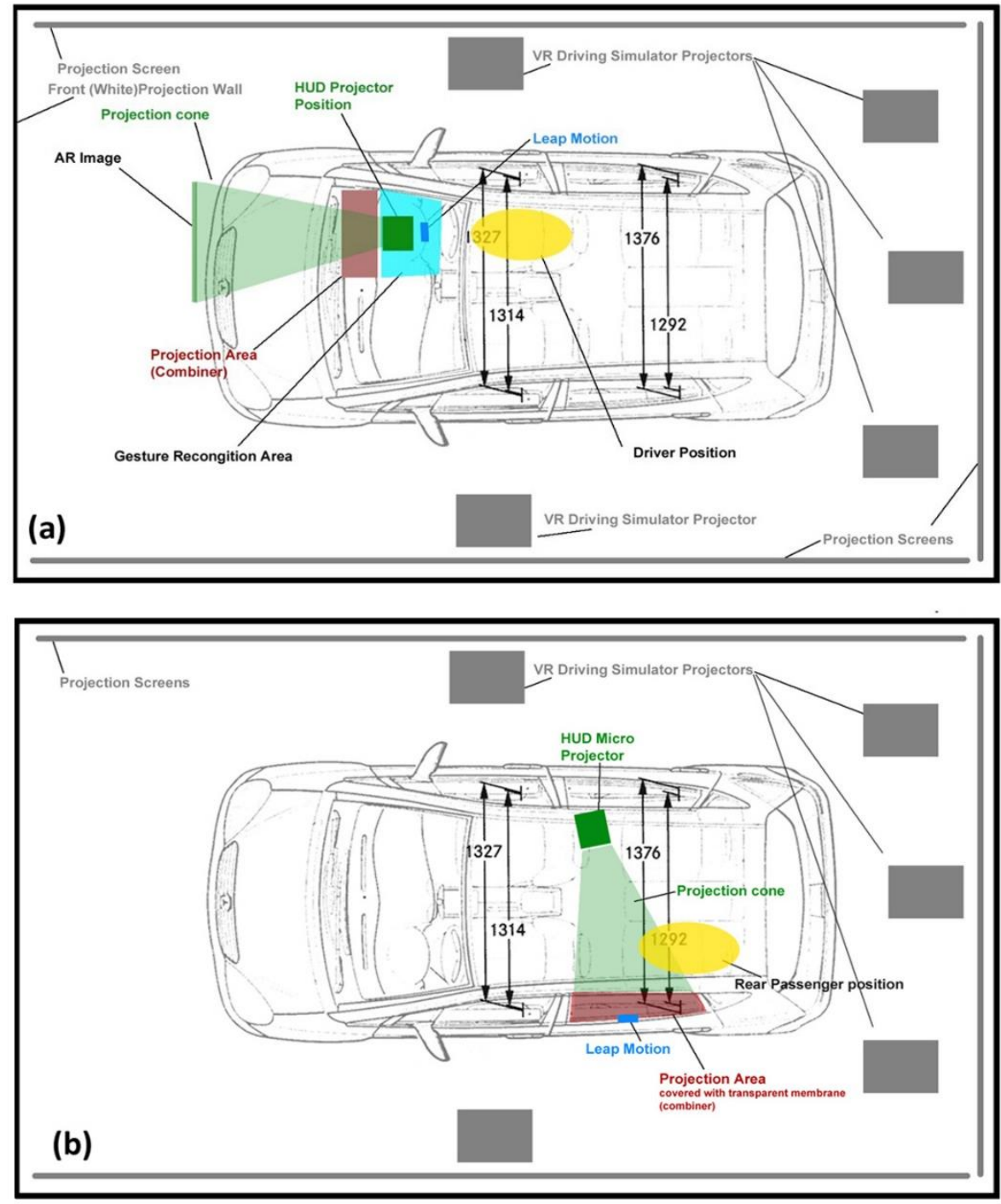

Fig. 4. Top view schematic of the Virtual Reality Driving Simulator laboratory (VRDS Lab) during the user evaluations of the two AR HUDS (a) Driver's and gesture recognition version (b) Passengers' side windows' version.

The simulator entails a real-life vehicle (Mercedes A-Class 2003 model) that is enclosed within a CAVE (Cave Automatic Virtual Environment) projection system and enriched with 5.1 surround audio and vibrotactile devices to imitate tarmac inconsistencies. The VRDS laboratory space and equipment offer a flexible and customisable environment for prototyping and evaluating various consumer electronics related to vehicles and road infrastructure as can be seen in Figure 4 a\&b. 


\section{Technology Acceptance Model (TAM) rationale}

As mentioned above the evaluation of driver's responses was achieved with the use of quantitive data such as vehicle's speed, deceleration/acceleration, collisions, lane positioning, gathered every 0.03 seconds. Yet, the driver's intention to use and adopt these new technologies and devices was unclear $[15,16]$. To investigate and clarify the users' intentions, we used the Technology Acceptance Model (TAM) following other similar consumer electronics studies [18-21]. TAM has been introduced in 1989 as a quantifiable method for predicting the usability and potential usage of new technologies and products [22]. Since then, TAM has been widely used by several industries that produce consumer electronics and software or embed them to other products. The TAM expands from the Theory of Reasoned Action (TRA) which is primarily employed to identify and predict human behavioural intentions by analysing, intentions, attitudes, and rules that lead the human to believe that particular behaviours could result in specific outcomes [23]. As such TAM can be used as a predictive modelling method that could investigate particular variables (i.e., constructs) that aim to identify user acceptability of products and outcomes.

The default version of TAM measures two theoretical constructs namely: ease of use "the degree to which a person believes that using a particular system would be free of efforts", and usefulness of the technology as the main determinants of system acceptance [22]. The perceived ease of use, usefulness and entertainment are the main factors that influence the customer's attitude towards new and emerging technology outputs [24]. The relation between a user and a product/interface system can be predicted by the perceived ease of use which could influence the perceived usefulness as depicted in Figure 5.

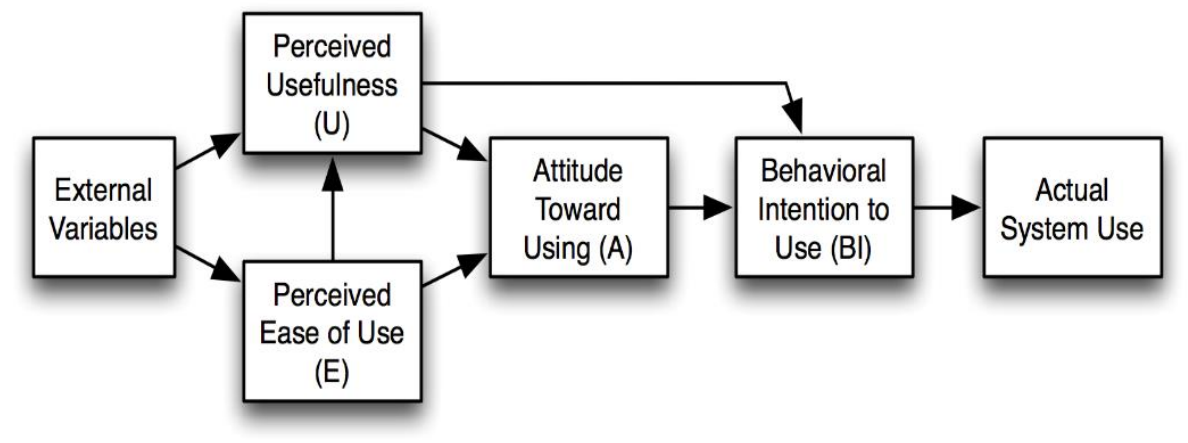

Fig. 5. First modified version of Technology Acceptance Model TAM [22].

Although the aforementioned variables are the essential constructs that could explain the acceptability of technologies and products, additional variables could contribute towards the formation of attitudes and views towards technological advancements [21]. This ability to incorporate bespoke constructs in a modular manner provides muchneeded flexibility to the TAM for accommodating different variables depending on the technology products, and the relevant users' population. 
In addition, previous studies demonstrated that several other common construct variables can be used to gauge technology adoption and acceptance, such as Behavioural Intention (BI), Attitude Towards Technology (ATT), and Anxiety (ANX) [9,25, 26].

As such research studies that investigate different technologies and outcomes such as electronics, engineering, medical, and e-commerce applications could enhance the main TAM structure by adding new constructs, designed to reveal users' behavioural intentions (BI) for specific technological products and services. Yet, it could be argued that the users' BI to use a product doesn't necessarily reflect the real-life, actual usage outcome. To this end, previous studies revealed that the BI is likely to be correlated with actual usage. In contrast, the main TAM constructs (i.e., PEU and PU) are less likely to be correlated with actual usage and as such caution is advisable when these constructs are utilised outwith the original context that the TAM was intended to be used [27]. In the automotive consumer electronics domain, a variety of TAM structures have been modified and employed to identify the user's intentions to use and ultimately purchase specific electronic devices or the car itself [28-30].

To accommodate the individual factors/variables that affect users' BI, different studies can develop additional constructs that are integrated into the default TAM model constructs. The establishment of new constructs is based on the system characteristic and tasks' nature. For the particular case studies presented in this paper, two variations of the main TAM structure were used as described below:

(a) The AR HUD for the Driver used a modified TAM to include further constructs that were deemed essential in determining the usability aspects and the perceived risk of the proposed system. This TAM adhered to the previous TAM 2 structure and evaluations where the Attitude Towards Using (A) was excluded from the default structure [30-32]. Although the value of (A) is debated in previous studies, in this particular case it was considered unnecessary as the system under investigation, was in the initial development phase and any minor differences in the results wouldn't have a major impact. The additional construct Perceived Risk of Use (PRISK) is incorporated and measured in the original TAM structure consisting of the Perceived Usefulness (PU) and Perceived Ease of Use (PEOU) in relation to the user's Behavioural Intention (BI). The different hypotheses $(\mathrm{H})$ that affect the relationship between the constructs are described in detail as follows:

- H1: A driver's perceived usefulness of a HUD utilising contactless gestures while driving has a positive effect on his/her behavioural intention to use the system.

- H2: A driver's perceived ease-of-use of HUD with contactless gestures has a positive effect on his/her behavioural intention to use the car infotainment system.

- H3: A driver's perceived ease-of-use of HUD with contactless gestures has a positive effect on his/her perceived usefulness of the car infotainment system.

- H4: The increased perceived risk of an HDD with touch gestures in comparison to HUD with contactless gestures has a negative effect on his/her behavioural intention to use the car infotainment system.

- H5: The increased perceived risk of an HDD with touch gestures in comparison to HUD with contactless gestures has a negative effect on the usefulness of the system. 
- H6: The increased perceived risk of an HDD with touch gestures in comparison to HUD with contactless gestures has a negative effect on perceived ease of use of the system.

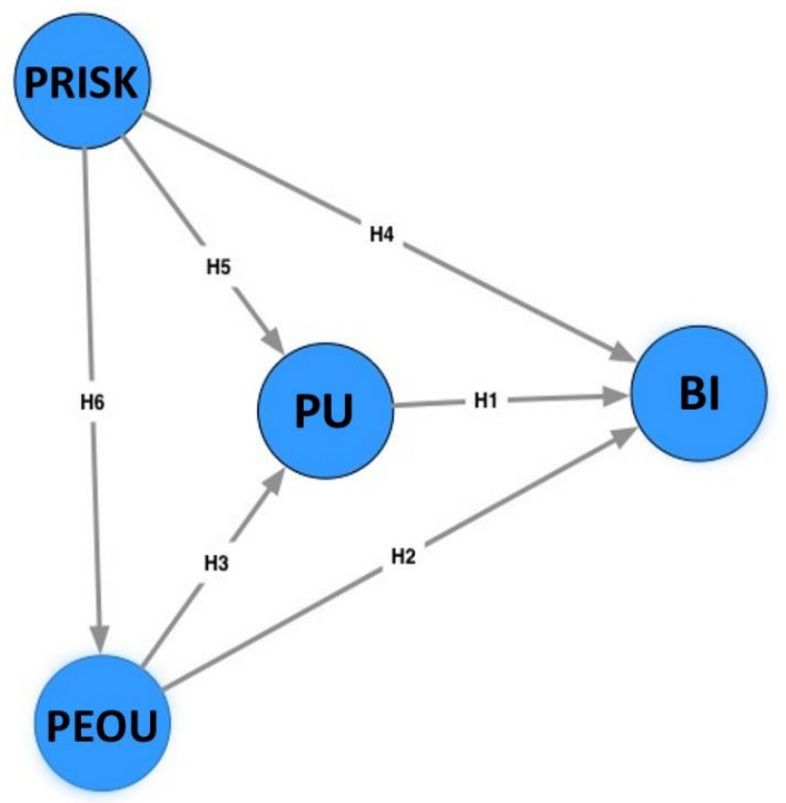

Fig 6. Case A: TAM for Driver's AR HUD with Contactless Gestures for infotainment system.

Based on TAM 2 and the custom TAM constructs used in this research were assessed by items of the questionnaire with PU having 9 items, PEOU with 7 items, Perceived risk with 5 items and BI with 4 items. After the trial, the user was asked to evaluate the system by going through the 25 questions using a 5-point Likert scale (5: Strongly agree, 5: Agree, 4: Neutral, 3: Disagree, 1: Strongly disagree).

(b) In contrast to the first case study, the Passengers' AR HUD used a modified model of TAM to include additional constructs. In this case, the Perceived Risk of Use (PRISK) has been replaced by the Perceived Entertainment value (PE) but the Attitude Towards Use (A) was maintained following closely the original TAM structure. Supplementary values were also investigated but not presented on this version, such as perceived presentation attractiveness (PPA), and perceived playfulness (PP) [29]. This factor (PE) has been incorporated into the model following previous TAM models that investigated the playfulness and enjoyment factors of specific technologies as is illustrated in Figure 7 [28-32]. 


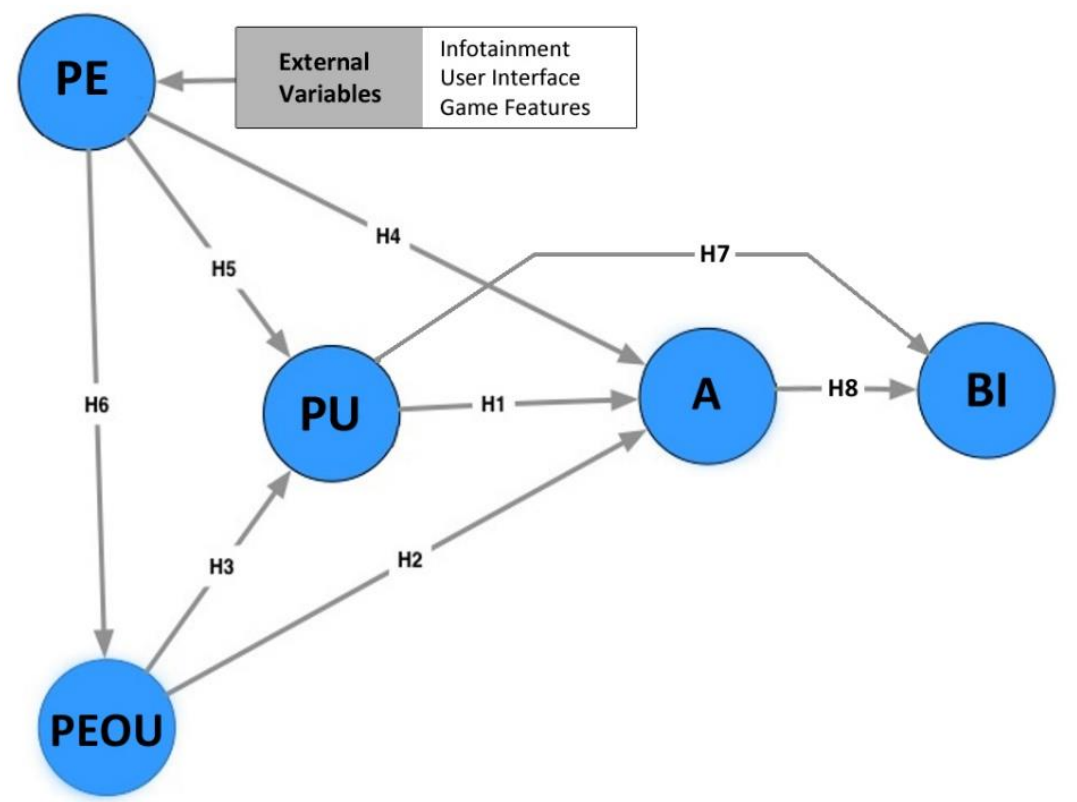

Fig 7. Case B: TAM for Passengers' AR HUD for infotainment system.

The different hypotheses $(\mathrm{H})$ that affect the relationship between the constructs are described in detail as follows:

- H1: A passenger's perceived usefulness (PU) of the AR HUD system positively affects his/her behavioural intention (BI) to use the system.

- H2: A passenger's perceived ease-of-use (PEOU) of the AR HUD system positively affects his/her behavioural intention (BI) to use the system.

- H3: A passenger's perceived ease-of-use (PEOU) of the AR HUD interface design will positively affect the participants' perceived usefulness (PU) of the system.

- H4: The perceived entertainment (PE) and educational value of the AR HUD in comparison to traditional means (i.e., smartphones/tablets, talking to the driver/passengers) will positively affect the participants' attitude of use (A) the proposed system.

- H5: The perceived entertainment (PE) and educational value of the AR HUD in comparison to traditional means (i.e., smartphones/tablets, talking to the driver/passengers) will positively affect the participants' perceived use (PU).

- H6: The perceived entertainment (PE) and interface design of the AR HUD in comparison to traditional means (i.e., smartphones/tablets, talking to the driver/passengers) will positively affect the participants' perceived use (PU).

- H7: A passengers' perceived usefulness (PU) of the AR HUD utilizing during commuting/trip will positively affect the participants' behavioural intention (BI) to use the system.

- H8: A passengers' attitude of use (A) of the AR HUD during commuting/trip will positively affect the participants' behavioural intention (BI) to use the system. 
In a similar mantra the AR Passengers' HUD employed a customised TAM, the research model for study (a), examines 5 constructs and 8 hypotheses' items. By the completion of the driving simulation experiment, the users' responded to 25 questions using the same 5-point Likert scale as per the previous case.

As this paper describes the rationale behind the combined use of VR simulations and custom TAM for the evaluation of prototype consumer electronics it is not in the remit of this work to analyse in detail the aforementioned TAM results but to present different options and TAM structures that could support future similar studies. The following section offers the main highlights and points of interest of this work.

\section{$5 \quad$ VR Simulations, TAM Results \& Discussion}

The TAM constructs proposed for both studies were assessed for their validity and reliability by employing descriptive analysis in SPSS. The internal consistency of all items was measured with Cronbach's alpha which is a value that calculates the coefficient of reliability. The Cronbach alpha value was above .7 for both studies which are considered acceptable. Cronbach's alpha coefficient for each construct is above .7 and ranges between 0.720 to 0.826 . The mean value of each item depicts the overall consistency and has been calculated for each item. The mean value of each TAM construct and its items is above 3.5 which is acceptable and proves that the accumulated data is consistent. The individual hypotheses $(\mathrm{H})$ for both cases were examined using regression analysis. The hypotheses testing values presented $\mathrm{p}$ values and correlation coefficient in the significant range $(\mathrm{p}<0.01$ and a correlation coefficiency above 0.5$)$ as required to support the hypotheses.

Irrelevantly to the TAM structure of choice (with or without the Attitude of Use) both studies presented valuable, measurable feedback which informed the immediate changes on the prototype applications. The subjective suggestions and the experimenters' observations verified further the users' responses whilst the quantitative data related to collision occurrences and driver's RTs also reinforced the TAM results. On some limited occasions, it was identified, a disparity between the users' BI and the actual performance achieved (for collision avoidance) with the prototype devices. Although these were negligible in the particular samples of users, 50 for each system evaluation, it would be of interest to explore further the reason and outputs that affected the users' BI.

As described in the previous section in a simulated synthetic environment it is feasible to reconstruct almost an infinite number of variables with no safety infringes. Furthermore, the system development could be achieved and re-evaluated on the spot and users' feedback could be applied significantly faster than in real-life working prototypes. A physical prototype would be eventually developed for the final product testing, yet, all the intermediate major or minor alterations could be applied in a considerably cost-effective manner through simulation [33-36].

In particular, human factors engineering attributes could be applied promptly throughout every stage of the development. Digital human modelling and accurate 
environment visualisation can provide the product engineers with crucial information concerning the benefits or problems that might appear in the real product. Identifying and resolving the potential issues well in advance offer a significant advantage to the typical testing environments and processes.

Additionally, VR can be employed also in cases that need to imitate the depth of field or various physical conditions, weather conditions and AI collision scenarios $[2,13,14,35]$.

Another significant attribute of VR simulation is the ability to incorporate any object (3D model) into the testing environment with no physical constraints as weight and overall size limitations. The drawback of VR simulations is that the initial 3D modelling and programming of interactions and physics could be an elaborate process, however, any future required changes could be applied rapidly and at a lesser cost than a physical prototype. On rare occasions, users could also demonstrate motion sickness if the evaluation of the prototype product requires the user to move in the virtual environment.

\section{Conclusions}

The paper presented a pipeline for the evaluation of vehicular consumer electronics with the use of VR driving simulators and customized Technology Acceptance Models. The paper discussed the flexibility of the VR simulators and the diversity between the products, actions and environments that could be replicated in a synthetic setting as well as the acceptance of such technologies by the prospective users.

In addition, this paper presented the virtual simulation requirements of two prototype multimodal AR HUD systems that both aim to reduce driver distraction either by the contemporary infotainment devices or by the interaction with the passengers. The evaluation of both systems was performed by 50 users and resulted in improving the driver's response time and situational awareness as the collision occurrences were reduced significantly in both cases.

The evaluation of both prototype systems has been accommodated in a high-fidelity full-scale VR driving simulator developed to replicate realistically driving scenarios of high probability collisions. In future work, we intend to exchange the TAM structures for the two studies and re-evaluate the proposed AR HUD systems aiming to identify potential differences in the user's behavioural intentions with and without the attitude towards use (A) construct.

\section{References}

1. Falcão C.S., Soares M.M., (2013). Application of Virtual Reality Technologies in Consumer Product Usability. In: Marcus A. (eds) Design, User Experience, and Usability. Web, Mobile, and Product Design. DUXU 2013. Lecture Notes in Computer Science, vol 8015. Springer, Berlin, Heidelberg. https://doi.org/10.1007/978-3-642-39253-5_37.

2. Charissis V., Ramsay J., Sharples B., Naef M., \& Jones B.S., (2008). 3D Stereoscopic Design of Submersive Rescue Vehicle and Rescue Mission Simulation, in International 
Conference of Warship 2008: Naval Submarines, The Royal Institution of Naval Architects, pp.13-19, Glasgow, UK.

3. Karapanos E., (2013). User Experience Over Time. In: Modeling Users' Experiences with Interactive Systems. Studies in Computational Intelligence, vol 436. Springer, Berlin, Heidelberg. https://doi.org/10.1007/978-3-642-31000-3_4

4. Lagoo R., Charissis V., and Harrison D. K., (2019). Mitigating Driver's Distraction: Automotive Head-Up Display and Gesture Recognition System, IEEE Consumer Electronics Magazine, vol8, no 5, pp 79-85, DOI: 10.1109/MCE.2019.2923896

5. Wang S., Charissis V., Lagoo R., Campbell J. and Harrison D.K., (2019). Reducing Driver Distraction by Utilising Augmented Reality Head-Up Display System for Rear Passengers, IEEE International Conference on Consumer Electronics (ICCE), Las Vegas, USA, DOI: 10.1109/ICCE.2019.8661927.

6. Altarteer S. and Charissis V., (2019). Technology Acceptance Model for 3D Virtual Reality System in Luxury Brands Online Stores", IEEE Access Journal, vol 7, pp 64053-64062, DOI: 10.1109/ACCESS.2019.2916353

7. Andrae A.S.G. and Andersen O., (2010). Life cycle assessments of consumer electronics are they consistent?. Int J Life Cycle Assess 15, 827-836 https://doi.org/10.1007/s11367010-0206-1

8. Lin Kuo-Yi, Yu Pei-I A., Chu Pei-Chun and Chien Chen-Fu, (2017). User experience-based design of experiments for new product development of consumer electronics and an empirical study, Journal of Industrial and Production Engineering, 34:7, 504-519, DOI: $10.1080 / 21681015.2017 .1363089$

9. Venkatesh V, Morris MG, Gordon BD, et al. (2003). User acceptance of information technology: toward a unified view. MIS Q.;27(3):425-478.

10. Wang S., Charissis V., Harrison D.K., (2017). Augmented Reality Prototype HUD for Passenger Infotainment in a Vehicular Environment", in Advances in Science, Technology and Engineering Systems Journal, Vol. 2, No. 3, 634-641.

11. Okumura, H., Hotta, A., Sasaki, T., Horiuchi, K., Okada, N., (2018). Wide field of view optical combiner for augmented reality head-up displays, 2018 IEEE International Conference on Consumer Electronics (IEEE ICCE).

12. Wang J., Wang W., Hansen P., Li Y., You F. (2020) The Situation Awareness and Usability Research of Different HUD HMI Design in Driving While Using Adaptive Cruise Control. In: Stephanidis C., Duffy V.G., Streitz N., Konomi S., Krömker H. (eds) HCI International 2020 - Late Breaking Papers: Digital Human Modeling and Ergonomics, Mobility and Intelligent Environments. HCII 2020. Lecture Notes in Computer Science, vol 12429. Springer, Cham. https://doi.org/10.1007/978-3-030-59987-4_17

13. Charissis V., Falah J., Lagoo R., Alfalah SFM., Khan S., Wang S., Altarteer S., Larbi KB., Drikakis D., (2021). Employing Emerging Technologies to Develop and Evaluate In-Vehicle Intelligent Systems for Driver Support: Infotainment AR HUD Case Study. Applied Sciences. 2021; 11(4):1397. https://doi.org/10.3390/app11041397

14. Wu W., Blaicher F., Yang J., Seder T. and Cui D., (2009). A prototype of landmark-based car navigation using a full-windshield head-up display system, In: AMC '09: Proceedings of the 2009 workshop on Ambient media computing, October 2009 pp. 21-28 https://doi.org/10.1145/1631005.1631012

15. Charissis V., and Papanastasiou S., (2010). Human-Machine Collaboration Through Vehicle Head-Up Display Interface, International Journal of Cognition, Technology and Work, P. C. Cacciabue and E. Hollangel (eds.) Springer London Ltd Volume 12, Number 1, pp 41-50, DOI: 10.1007/s10111-008-0117. 
16. Charissis V., Papanastasiou S., Chan W., and Peytchev E., (2013). Evolution of a full-windshield HUD designed for current VANET communication standards, IEEE Intelligent Transportation Systems International Conference (IEEE ITS), The Hague, Netherlands, pp. 16371643, DOI: 10.1109/ITSC.2013.6728464.

17. Charissis V., Papanastasiou S., Mackenzie L., Arafat S. (2011) Evaluation of Collision Avoidance Prototype Head-Up Display Interface for Older Drivers. In: Jacko J.A. (eds) Human-Computer Interaction. Towards Mobile and Intelligent Interaction Environments. HCI 2011. Lecture Notes in Computer Science, vol 6763. Springer, Berlin, Heidelberg. https://doi.org/10.1007/978-3-642-21616-9_41

18. Barker J., (2009), Driven to Distraction: Children's Experiences of Car Travel, Brunel University, UK, DOI 10.1080/17450100802657962.

19. Planing P., Britzelmaier B., (2012). Understanding Consumer Acceptance of Advanced Driver Assistance Systems - A Qualitative Study on the German Market, International Journal of Sales Retailing and Marketing

20. Lin Kuo-Yi, Pei-I Yu A., Chu Pei-Chun and Chien Chen-Fu, (2017). User experience-based design of experiments for new product development of consumer electronics and an empirical study, Journal of Industrial and Production Engineering, 34:7, 504-519, DOI: 10.1080/21681015.2017.1363089

21. Altarteer S., Charissis V., Harrison D., Chan W. (2016). Product customisation: virtual reality and new opportunities for luxury brands online trading. In Proceedings of the $21 \mathrm{st} \mathrm{In-}$ ternational Conference on Web3D Technology (Web3D '16). Association for Computing Machinery, New York, NY, USA, 173-174. DOI:https://doi.org/10.1145/2945292.2945317

22. Davis F.D., Bagozzi R.P. and Warshaw P.R., (1989). User acceptance of computer technology: a comparison of two theoretical models. Management science, 35(8), pp.982-1003.

23. Madden T.J., Ellen P.S., Ajzen I., (1992). A Comparison of the Theory of Planned Behavior and the Theory of Reasoned Action. Personality and Social Psychology Bulletin. 1992;18(1):3-9. doi:10.1177/0146167292181001

24. Kim J., Forsythe S., (2008). Sensory enabling technology acceptance model (SE-TAM): a multiple-group structural model comparison, Psychological Marketing, 25(9), pp. 901-922.

25. Fetscherin M., and Lattemann C., (2008). User Acceptance of Virtual Worlds, Journal of Electronic Commerce Research, Vol. 9, No. 3, pp. 231-242.

26. Altarteer S., Charissis V., Harrison D., and Chan W., (2013) Interactive Virtual Reality Shopping and the Impact in Luxury Brands. In: Shumaker R. (eds) Virtual, Augmented and Mixed Reality. Systems and Applications. VAMR 2013. Lecture Notes in Computer Science, vol 8022. Springer, Berlin, Heidelberg.

27. Turner M., Kitchenham B., Brereton P., Charters S., Budgen D., (2010). Does the technology acceptance model predict actual use? A systematic literature review, Information and Software Technology, Vol 52, no 5, pp. 463-479, https://doi.org/10.1016/j.infsof.2009.11.005.

28. Planing P., and Britzelmaier B., (2012). Understanding Consumer Acceptance of Advanced Driver Assistance systems - A Qualitative Study on the German Market, in International Journal of Sales, Retailing and Marketing, pp. 32-40.

29. Planing P., (2014). Innovation Acceptance: The Case of Advanced Driver-Assistance Systems, Springer Gabler.

30. Legris P., Ingham J., Collerette P., (2003). Why do people use information technology? A critical review of the technology acceptance model. In: Information Management. Vol. 40, pp. 191-204.

31. Surendran P., (2012). Technology Acceptance Model: A Survey of Literature", International Journal of Business and Social Research (IJBSR), Vol. 2, No.4, pp. 175-178 
32. Marangunić N., Granić A., (2015). Technology acceptance model: a literature review from 1986 to 2013. Univ Access Inf Soc 14, 81-95.

33. Choi S., Jung K. and Noh S.D., (2015). Virtual reality applications in manufacturing industries: Past research, present findings, and future directions. Concurrent Engineering. 2015;23(1):40-63. doi:10.1177/1063293X14568814

34. Berg L.P., Vance J.M., (2017). Industry use of virtual reality in product design and manufacturing: a survey. Virtual Reality 21, 1-17. https://doi.org/10.1007/s10055-016-0293-9

35. Frank M., Drikakis D., and Charissis V., (2020), Machine-Learning Methods for Computational Science and Engineering. Computation, 8, 15.

36. Choudhry A., Premchand A., (2021). Digital Transformation Using Immersive Technologies in Manufacturing and Utilities. In: Favorskaya M., Mekhilef S., Pandey R., Singh N. (eds) Innovations in Electrical and Electronic Engineering. Lecture Notes in Electrical Engineering, vol 661. Springer, Singapore. https://doi.org/10.1007/978-981-15-4692-1_33 